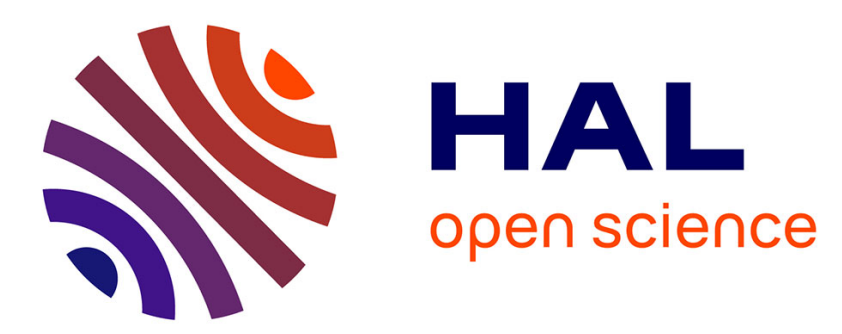

\title{
Application of the Proper Generalized Decomposition to Solve MagnetoElectric Problem
}

Thomas Henneron, Stephane Clenet

\section{To cite this version:}

Thomas Henneron, Stephane Clenet. Application of the Proper Generalized Decomposition to Solve MagnetoElectric Problem. IEEE Transactions on Magnetics, 2017, pp.1-4. 10.1109/TMAG.2017.2762702 . hal-01691121

\section{HAL Id: hal-01691121 \\ https://hal.science/hal-01691121}

Submitted on 23 Jan 2018

HAL is a multi-disciplinary open access archive for the deposit and dissemination of scientific research documents, whether they are published or not. The documents may come from teaching and research institutions in France or abroad, or from public or private research centers.
L'archive ouverte pluridisciplinaire HAL, est destinée au dépôt et à la diffusion de documents scientifiques de niveau recherche, publiés ou non, émanant des établissements d'enseignement et de recherche français ou étrangers, des laboratoires publics ou privés. 


\title{
Application of the Proper Generalized Decomposition to Solve MagnetoElectric Problem
}

\author{
T. Henneron ${ }^{1}$ and S. Clénet ${ }^{1}$ \\ ${ }^{1}$ Univ. Lille, Centrale Lille, Arts et Metiers ParisTech, HEI, EA 2697 - L2EP, F-59000 Lille, France
}

\begin{abstract}
Among the model order reduction techniques, the Proper Generalized Decomposition (PGD) has shown its efficiency to solve a large number of engineering problems. In this article, the PGD approach is applied to solve a multi-physics problem based on a magnetoelectric device. A reduced model is developed to study the device in its environment based on an Offline/Online approach. In the Offline step, two specific simulations are performed in order to build a PGD reduced model. Then, we obtain a model very well fitted to study in the Online stage the influence of parameters like the frequency or the load. The reduced model of the device is coupled with an electric load (R-L) to illustrate the possibility offered by the PGD.
\end{abstract}

Index Terms - Finite element method, Magnetoelectric problem, Proper Generalized Decomposition.

\section{INTRODUCTION}

$\mathrm{T}$ O reduce the computational time of numerical models in the time or frequency domain, Model Order Reduction (MOR) methods have been developed and presented in the literature. These approaches have been mainly used to study a large number of devices in mechanics. In this field, the Proper Generalized Decomposition method has been largely developed since the early 2000's [1][2]. In computational electromagnetics, the PGD approach has been applied with a fuel cell polymeric membrane model [3]. In static electromagnetism, the nonlinear behavior of a Soft Magnetic Composite Material and of a three phase transformer has been studied [4][5]. In magneto-quasistatics, the skin effect in a rectangular slot or in a conducting plate and a squirrel cage induction machine at standstill have been addressed [6][7]. Multi-physic problems have been also considered like a magneto-thermal problem [8], a piezoelectric energy harvester [9] or a magnetoelectric device at no-load [10].

The principle of the PGD method consists in expressing the solution by a sum of functions depending on each parameter of the problem, so-called modes. Each mode is determined by an iterative procedure and depends on the previous modes. In the case of systems of partial differential equations in the frequency domain, the PGD approach approximates the solution by a sum of functions separable in frequency and space. In this paper, we propose to apply the PGD approach to study a magnetoelectric device coupled with any electrical circuit. An Offline/Online approach is introduced. In the Offline step, two specific configurations of the problem without electric load are solved with the PGD in order to build a reduced model. The PGD formulation proposed is different to this presented in [10]. In fact, the global quantities like the voltage, the magnetic flux and the electric charge appear explicitly in the formulation. In the Online step, the reduced model of the device is coupled with an electric load (R-L). This model is very well fitted to study the influence of parameters like the frequency or the load. The results obtained with the PGD reduced model are compared in terms of accuracy and of computational time with the full model.

\section{MagnetoElectric Problem}

Let us consider a domain $D$ with its boundary $\Gamma$ holding a 2D sensor composed of magnetostrictive (MM) and piezoelectric (PZT) materials (Fig. 1). An external harmonic magnetic flux $\Phi$ is imposed. The sensor is clamped in 2 points where the displacement is imposed to zero in the two directions. Due to the symmetry of the studied problem, the electric potential is equal to $\mathrm{v}_{0}$ on $\Gamma_{\mathrm{v} 1}$ and to $-\mathrm{v}_{0}$ on $\Gamma_{\mathrm{v} 2}$.

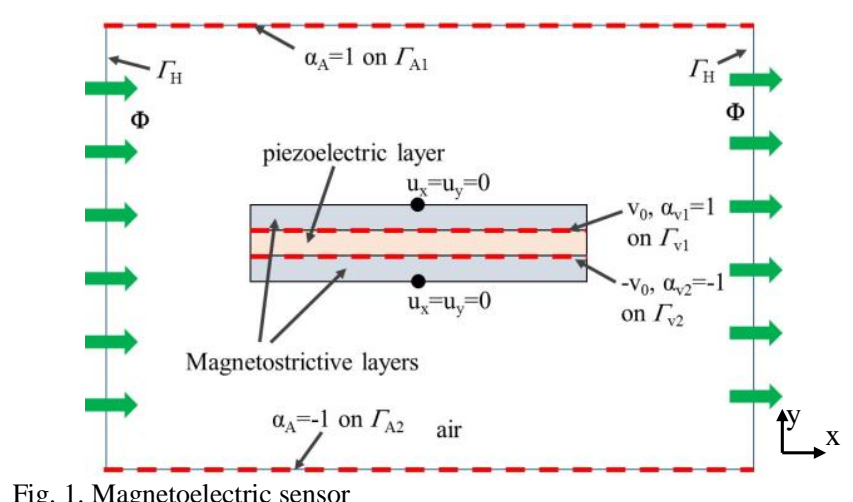

By neglecting the external forces, the eddy and displacement currents, the system of equations to be solved, based on the mechanical equilibrium equation as well as the magnetostatics and electrostatics ones, becomes

$$
\begin{gathered}
\operatorname{div} \mathbf{T}+\rho \omega^{2} \mathbf{u}=0, \\
\operatorname{curl} \mathbf{E}=0 \text { (a), } \operatorname{div} \mathbf{D}=0 \text { (b), } \\
\text { curl } \mathbf{H}=0 \text { (a), } \operatorname{div} \mathbf{B}=0 \quad \text { (b), }
\end{gathered}
$$

with $\mathbf{T}$ the stress tensor, $\mathbf{u}$ the displacement, $\mathbf{D}$ the electric induction, $\mathbf{E}$ the electric field, $\mathbf{H}$ the magnetic field, $\mathbf{B}$ the magnetic flux density, $\rho$ the mass density and $\omega$ the angular frequency. As we consider a $2 \mathrm{D}$ problem, we have curl $\mathbf{X}=$ $\left(\partial_{\mathrm{y}} \mathrm{X}_{\mathrm{z}}-\partial_{\mathrm{x}} \mathrm{X}_{\mathrm{z}}\right)^{\mathrm{t}}$. Therefore, in the following, the curl equations can be modified in order to introduce the gradient operator $\operatorname{grad}_{\mathrm{R}}$. The constitutive laws of MM and PZT materials are:

$$
\begin{gathered}
\mathbf{T}=\mathrm{c} \mathbf{S}-\tau^{\mathrm{t}} \mathbf{E}-\mathrm{h}^{\mathrm{t}} \mathbf{B}, \\
\mathbf{D}=\varepsilon \mathbf{E}+\tau \mathbf{S}, \\
\mathbf{H}=v \mathbf{B}-\mathrm{h} \mathbf{S},
\end{gathered}
$$


with $\mathbf{S}$ the strain tensor, $\mathrm{c}$ the stiffness tensor, $\tau$ the piezoelectric coefficients, $\varepsilon$ the electric permittivity, $v$ the magnetic reluctivity and $h$ the relative piezomagnetic coefficients defined by $\mathrm{h}=\mathrm{e} \cdot \mathrm{v}$ with $\mathrm{e}$ the piezomagnetic coefficients . To solve the problem, a formulation in terms of potentials can be used. From (2-a) and (3-b) and by assuming small deformations, we have

$$
\begin{gathered}
\mathbf{E}=-\operatorname{grad}-\mathrm{v}_{0}\left(\operatorname{grad}_{\mathrm{v} 1}+\operatorname{grad}_{\mathrm{v} 2}\right) \\
\mathbf{B}=-\operatorname{grad}_{\mathrm{R}} \mathbf{A}-\operatorname{\Phi grad}_{\mathrm{R}} \alpha_{\mathrm{A}} \\
\mathbf{S}=\frac{1}{2}\left(\operatorname{gradu}+\operatorname{grad}^{\mathrm{t}} \mathbf{u}\right)=\boldsymbol{D u}
\end{gathered}
$$

with v the electric potential defined in $D-\Gamma-\Gamma_{\mathrm{v} 1}-\Gamma_{\mathrm{v} 2}, \mathrm{v}_{0}$ (resp. $\left.\mathrm{v}_{0}\right)$ the electric potential on $\Gamma_{\mathrm{v} 1}\left(\right.$ resp. $\left.\Gamma_{\mathrm{v} 2}\right), \alpha_{\mathrm{v} 1}$ and $\alpha_{\mathrm{v} 2}$ scalar functions equal to 1 and -1 on $\Gamma_{\mathrm{v} 1}$ and $\Gamma_{\mathrm{v} 2}$ respectively and 0 elsewhere, $\mathbf{A}$ the magnetic potential defined on $D-\Gamma_{\mathrm{A} 1}-\Gamma_{\mathrm{A} 2}$ and $\alpha_{\mathrm{A}}$ a scalar function equal to 1 on $\Gamma_{\mathrm{A} 1},-1$ on $\Gamma_{\mathrm{A} 2}$ and 0 elsewhere. Then, we seek for the solutions $\mathbf{v}, \mathbf{A}$ and $\mathbf{u}$ in the space domain $D$ and in the angular frequency interval $\left[\omega_{\min }: \omega_{\max }\right]$.

\section{Proper Generalized Formulation}

The PGD method consists in approximating the solutions by a sum of separable functions in frequency and space. Then, $v$, $\mathbf{A}$ and $\mathbf{u}$ are approximated by separated forms of space and frequency functions,

$\mathrm{v} \approx \sum_{\mathrm{j}=1}^{\mathrm{M}} \mathbf{R}_{\mathrm{j}}^{\mathrm{v}}(\mathbf{x}) \mathrm{S}_{\mathrm{j}}^{\mathrm{v}}(\omega), \mathbf{A} \approx \sum_{\mathrm{j}=1}^{\mathrm{M}} \mathbf{R}_{\mathrm{j}}^{\mathrm{A}}(\mathbf{x}) \mathrm{S}_{\mathrm{j}}^{\mathrm{A}}(\omega)$ and $\mathbf{u} \approx \sum_{\mathrm{j}=1}^{\mathrm{M}} \mathbf{R}_{\mathrm{j}}^{\mathrm{u}}(\mathbf{x}) \mathrm{S}_{\mathrm{j}}^{\mathrm{u}}(\omega)$

with $\mathbf{x} \in D, \omega \in\left[\omega_{\min }: \omega_{\max }\right]$ and $\mathrm{M}$ the number of modes of the expansions. To apply the PGD approach, we consider a weak formulation on $D \times\left[\omega_{\min }: \omega_{\max }\right]$ of (1), (2-b) and (3-a). In the following, we suppose that the electric charge $Q$ is imposed. Then, we have:

$$
\begin{gathered}
\int_{\omega_{\min }}^{\omega_{\max }} \int_{D} \mathbf{u}^{\prime} \cdot\left[\operatorname{div} \mathbf{T}+\rho \omega^{2} \mathbf{u}\right] \mathrm{d} D \mathrm{~d} \omega=0 \\
\int_{\omega_{\min }} \int_{D} \mathbf{v}^{\prime} \cdot \operatorname{div} \mathbf{D} \mathrm{d} D \mathrm{~d} \omega=0 \\
\int_{\omega_{\min }}^{\omega_{\max }} \int_{D} \mathbf{A}^{\prime} \cdot \operatorname{curl} \mathbf{H} \mathrm{d} D \mathrm{~d} \omega=0 \\
\int_{\omega_{\min }}^{\omega_{\max }} \int_{D} \alpha_{\mathrm{v} 1} \cdot \operatorname{div} \mathbf{D} \mathrm{d} D \mathrm{~d} \omega=\int_{\omega_{\min }}^{\omega_{\max }} \mathrm{Q} \mathrm{d} \omega \\
\int_{\omega_{\min }}^{\int_{\max }} \alpha_{\mathrm{v} 2} \cdot \operatorname{div} \mathbf{D} \mathrm{d} D \mathrm{~d} \omega=-\int_{\omega_{\min }}^{\omega_{\max }} \mathrm{Q} \mathrm{d} \omega
\end{gathered}
$$

with $\mathbf{u}^{\prime}, \mathrm{v}^{\prime}$ and $\mathbf{A}^{\prime}$ 'test functions defined in the same spaces of the functions $\mathbf{u}, \mathbf{v}$ and $\mathbf{A}$ respectively. To compute the functions $R_{j}^{1}$ and $S_{j}^{1}$ for $j \in[1: M]$ and $l=\{v, A, u\}$ and $v_{0}$, an iterative enrichment approach is used. At the $\mathrm{n}^{\text {th }}$ iteration, $\mathrm{v}_{\mathrm{n}}$, $\mathbf{A}_{\mathrm{n}}$ and $\mathbf{u}_{\mathrm{n}}$ are expressed as functions of $\mathrm{R}_{\mathrm{n}}^{1}$ and $S_{\mathrm{n}}^{1}$ and of the known previous approximations $\mathrm{v}_{\mathrm{n}-1}, \mathbf{A}_{\mathrm{n}-1}$ and $\mathbf{u}_{\mathrm{n}-1}$ such as
$\mathrm{v}_{\mathrm{n}}=\mathrm{R}_{\mathrm{n}}^{\mathrm{v}}(\mathbf{x}) \mathrm{S}_{\mathrm{n}}^{\mathrm{v}}(\omega)+\mathrm{v}_{\mathrm{n}-1}, \mathbf{A}_{\mathrm{n}}=\mathbf{R}_{\mathrm{n}}^{\mathrm{A}}(\mathbf{x}) \mathrm{S}_{\mathrm{n}}^{\mathrm{A}}(\omega)+\mathbf{A}_{\mathrm{n}-1}$ and $\mathbf{u}_{\mathrm{n}}=\mathbf{R}_{\mathrm{n}}^{\mathrm{u}}(\mathbf{x}) \mathrm{S}_{\mathrm{n}}^{\mathrm{u}}(\omega)+\mathbf{u}_{\mathrm{n}-1}$. Then, to compute the unknown functions $R_{n}^{1}, S_{n}^{1}$ and $v_{0}$, two sets of equations deduced from (11-15) are solved iteratively. In a first step, we assume that the functions $S_{\mathrm{n}}^{1}$ with $\mathrm{l}=\{\mathrm{v}, \mathrm{A}, \mathrm{u}\}$ and $\mathrm{v}_{0}$ are known in order to calculate the functions $\mathrm{R}_{\mathrm{n}}^{1}$. In $2 \mathrm{D}$, the functions are discretised in the nodal element space such as $\mathrm{R}_{\mathrm{n}}^{1}=\mathrm{W}^{1} R_{\mathrm{n}}^{1}$ for $\mathrm{l}=\{\mathrm{v}, \mathrm{A}, \mathrm{u}\}$ with $\mathrm{W}$ the vector which entries are the nodal functions and $R_{\mathrm{n}}^{1}$ the vector of the values at the nodes. Then, we solve

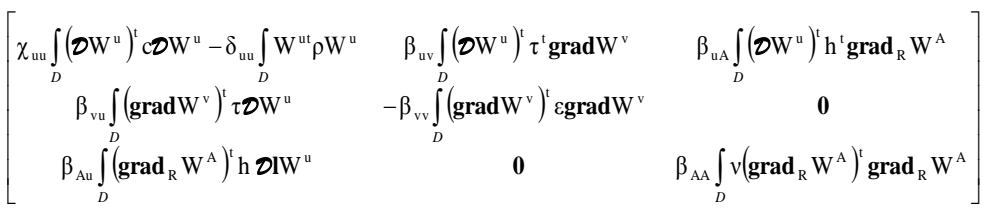

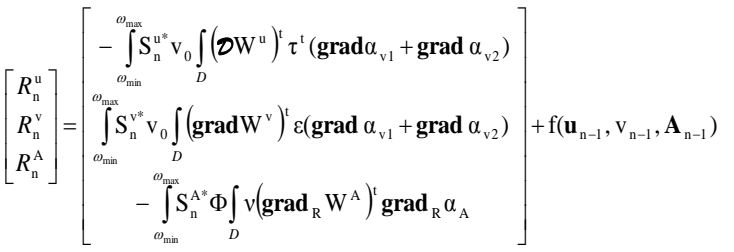

$$
\begin{aligned}
& \text { with } \chi_{\mathrm{uu}}=\int_{\omega_{\min }}^{\omega_{\max }}(1+\mathrm{j} \omega \alpha) S_{\mathrm{n}}^{\mathrm{u}^{*}} \mathrm{~S}_{\mathrm{n}}^{\mathrm{u}} \mathrm{d} \omega, \delta_{\mathrm{uu}}=\int_{\omega_{\min }}^{\omega_{\max }} \omega^{2} S_{\mathrm{n}}^{\mathrm{u}^{*}} S_{\mathrm{n}}^{\mathrm{u}} \mathrm{d} \omega \text { and } \\
& \beta_{\mathrm{k} 1}=\int_{\omega_{\min }}^{\omega_{\max }} S_{\mathrm{n}}^{\mathrm{k}^{*}} \mathrm{~S}_{\mathrm{n}}^{\mathrm{l}} \mathrm{d} \omega \quad \text { for } \mathrm{k}, \mathrm{l}=\{\mathrm{v}, \mathrm{A}, \mathrm{u}\} .
\end{aligned}
$$

Where $\alpha$ is the damping coefficient and $\mathrm{X}^{*}$ denotes the conjuguate of $X$. In a second step, the functions $S_{n}^{1}$ and $v_{0}$ are recomputed with the functions $R_{n}^{1}$ supposed to be known. Then, for each $\omega_{\mathrm{k}} \in\left[\omega_{\min }: \omega_{\max }\right]$, we have:

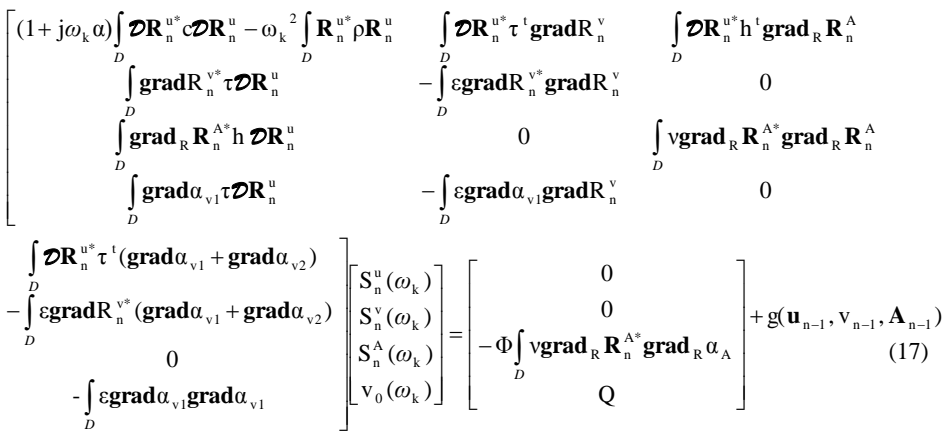

The two steps are repeated until convergence of all functions $R_{n}^{1}, S_{n}^{1}$ and $v_{0}$ with $l=\{v, A, u\}$. The number of modes $\mathrm{M}$ used to approximate the solutions is not known $a$ priori by the user. Then, a criterion is defined to stop the enrichment process. For example, this criterion can be based on the norm of the $n^{\text {th }}$ mode with respect to the norm of the first mode [1] or on quantities of interest [5][7][10]. The convergence of the enrichment process can be improved by introducing an update step of the frequency functions after each calculation of the new mode. This step enables to recompute an optimal subspace of functions orthogonal to the 
residual [1]. It consists in recomputing the functions $S_{j}^{1}$ for $\mathrm{j} \in[1: \mathrm{n}]$ with $\mathrm{l}=\{\mathrm{v}, \mathrm{A}, \mathrm{u}\}$ and $\mathrm{v}_{0}$ with respect to the functions $\mathbf{R}_{\mathrm{j}}^{1}$.

\section{APPLICATION}

In term of application, we consider the device presented in Fig. 1 and detailed in [10]. The 2D mesh is composed of 3283 nodes and 6525 triangles. The frequency interval is fixed at $\left[10^{4} ; 10^{5}\right] \mathrm{Hz}$ with 401 equidistributed values. The aim is to study the device coupled with an electrical load when the magnetic flux $\Phi$ is imposed. The quantities of interest are the voltage between the two electrodes (i.e. equal to $2 v_{0}$ ) and the maximal deformation along $\mathrm{x}$ and $\mathrm{y}$. Then, an Offline/Online approach is used. On the Offline step, a reduced model of the device without load is built applying the PGD presented in section III. On the Online step, the reduced model is coupled with an electrical load in order to study the influence of the load parameters on the quantities of interest.

\section{A. Offline Step: determination of the PGD reduced model}

The reduced model is determined by taking advantage of the superposition principle. Two specific configurations of the problem are considered. For each case, approximations of the solutions under the forms given by (10) are computed. For the first configuration, the magnetic flux $\Phi$ is imposed and the charge $\mathrm{Q}$ is fixed to zero. Then, the PGD formulation presented in the section III is applied. We obtain the PGD approximations: $\mathrm{v}_{0 \Phi}, \mathrm{v}_{\Phi} \approx \sum_{\mathrm{j}=1}^{\mathrm{M}} \mathrm{R}_{\mathrm{j} \Phi}^{\mathrm{v}}(\mathbf{x}) \mathrm{S}_{\mathrm{j} \Phi}^{\mathrm{v}}(\omega), \quad \mathbf{A}_{\Phi} \approx \sum_{\mathrm{j}=1}^{\mathrm{M}} \mathbf{R}_{\mathrm{j} \Phi}^{\mathrm{A}}(\mathbf{x}) \mathrm{S}_{\mathrm{j} \Phi}^{\mathrm{A}}(\omega)$ and $\mathbf{u}_{\Phi} \approx \sum_{\mathrm{j}=1}^{\mathrm{M}} \mathbf{R}_{\mathrm{j} \Phi}^{\mathrm{u}}(\mathbf{x}) \mathrm{S}_{\mathrm{j} \Phi}^{\mathrm{u}}(\omega)$.

Figure 2 presents the evolutions of the relative error on the electric potential $\mathrm{v}_{0 \Phi}$ and the maximal deformations $\operatorname{def}_{\mathrm{x} \Phi}$ and $\operatorname{def}_{\mathrm{y} \Phi}$ along $\mathrm{x}$ and $\mathrm{y}$ as functions of the number of modes. The relative error is given by

$$
\varepsilon_{\mathrm{r}} \mathrm{X}=\frac{\left\|\mathrm{X}_{\mathrm{ref}}-\mathrm{X}_{\mathrm{pgd}}\right\|_{2}}{\left\|\mathrm{X}_{\text {ref }}\right\|_{2}}
$$

with $\mathrm{X}$ the vector of discrete values of quantity of interest (i.e., $\mathrm{v}_{0 \Phi}, \operatorname{def}_{\mathrm{x} \Phi}$ or $\left.\operatorname{def}_{\mathrm{y} \Phi}\right)$. With a low number of modes, the magnitude of $\mathrm{v}_{0 \Phi}$ versus the frequency is close to the reference. With $\mathrm{M}=5$, the relative error is close to $0.01 \%$ and the speed up versus the full model is equal to 8 . To obtain good approximations of the maximal deformations, the number of modes must be greater, for $\mathrm{M}=16$, we have $\varepsilon_{\mathrm{r}} \operatorname{def}_{\mathrm{x} \Phi}<0.01 \%$ and $\varepsilon_{\mathrm{r}} \operatorname{def}_{\mathrm{y} \Phi}<0.01 \%$ with a speed up equal to 2.5. Figures 3 and 4 present the evolutions of the voltage magnitude and of the maximal deformation along $\mathrm{x}$ and $\mathrm{y}$ versus the frequency obtained from the PGD approximations for $M=16$. We can observe a phenomenon of resonance on $\mathrm{v}_{0} \Phi$ and $\operatorname{def}_{\mathrm{x} \Phi}$ or $\operatorname{def}_{\mathrm{y} \Phi}$.

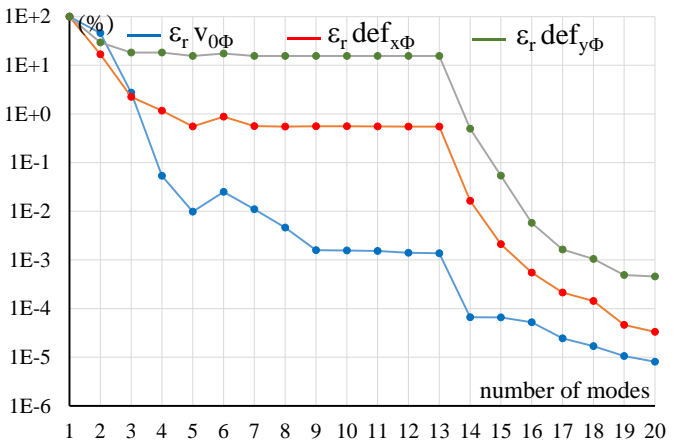

Fig. 2. Relative errors on the electric potential $v_{0 \Phi}$ and on the maximal deformations $\operatorname{def}_{\mathrm{x} \Phi}$ and def $\mathrm{y}_{\mathrm{y} \Phi}$ versus the number of modes

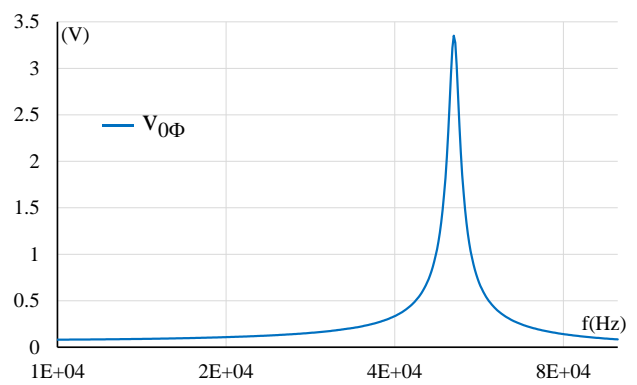

Fig. 3. Magnitude of the voltage versus the frequency.

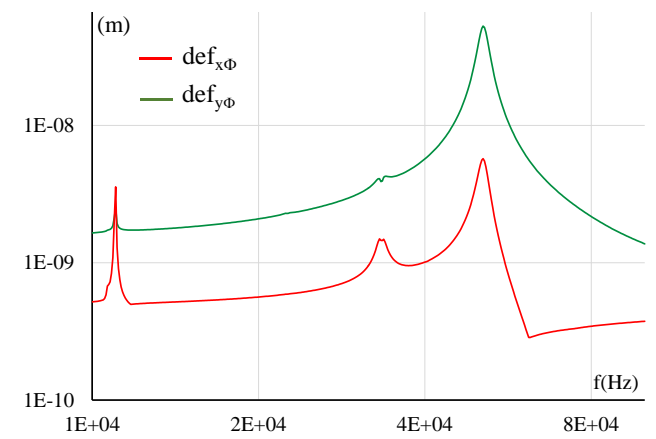

Fig. 4. Maximal deformations along $\mathrm{x}$ and $\mathrm{y}$ versus the frequency.

For the second configuration, the magnetic flux $\Phi$ is fixed to zero, the charge $\mathrm{Q}$ is imposed and the PGD approach is applied. The convergence of the PGD is similar to this of the first configuration. As the electric charge $\mathrm{Q}$ depends on the electrical load connected to the device, the approximations of the solutions are expressed as functions of $\mathrm{Q}$ such as: $\mathrm{v}_{0 \mathrm{Q}} \mathrm{Q}, \mathrm{v}_{\mathrm{Q}} \approx\left(\sum_{\mathrm{j}=1}^{\mathrm{M}} \mathrm{R}_{\mathrm{jQ}}^{\mathrm{v}}(\mathbf{x}) \mathrm{S}_{\mathrm{jQ}}^{\mathrm{v}}(\omega)\right) \mathrm{Q}, \mathbf{A}_{\mathrm{Q}} \approx\left(\sum_{\mathrm{j}=1}^{\mathrm{M}} \mathbf{R}_{\mathrm{jQ}}^{\mathrm{A}}(\mathbf{x}) \mathrm{S}_{\mathrm{jQ}}^{\mathrm{A}}(\omega)\right) \mathrm{Q}$ and $\mathbf{u}_{\mathrm{Q}} \approx\left(\sum_{\mathrm{j}=1}^{\mathrm{M}} \mathbf{R}_{\mathrm{jQ}}^{\mathrm{u}}(\mathbf{x}) \mathrm{S}_{\mathrm{jQ}}^{\mathrm{u}}(\omega)\right) \mathrm{Q}$. From two specific configurations of the problem, we can build a reduced model of the device depending on the electric charge. By applying the superposition theorem, the voltage $U$ between the two electrodes, $\mathbf{v}, \mathbf{A}$ and $\mathbf{u}$ are expressed by

$$
\begin{gathered}
\mathrm{U}=2 \mathrm{v}_{0}=2 \mathrm{v}_{0 \Phi}+2 \mathrm{v}_{0 Q} \mathrm{Q} \quad(\mathrm{a}), \mathrm{v}=\mathrm{v}_{\Phi}+\mathrm{v}_{\mathrm{Q}} \quad(\mathrm{b}), \\
\mathbf{A}=\mathbf{A}_{\Phi}+\mathbf{A}_{\mathrm{Q}} \text { (c) and } \mathbf{u}=\mathbf{u}_{\Phi}+\mathbf{u}_{\mathrm{Q}}(\mathrm{d}) .
\end{gathered}
$$

\section{B. Online Step: PGD reduced model of the device coupled with electric load}

We consider the device coupled with a load composed of a resistor R and of an inductance L (Fig. 5). 


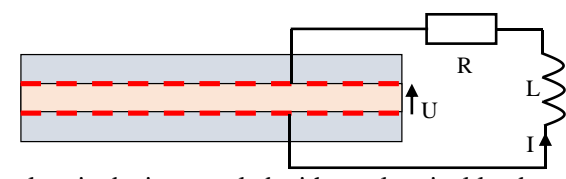

Fig. 5. Magnetoelectric device coupled with an electrical load

The device is modeled by the reduced model depending on the electric charge Q. Due to the load, a new coupling equation is added:

$$
\mathrm{U}+(\mathrm{R}+\mathrm{jL} \omega) \mathrm{I}=0 \text { with } \mathrm{I}=\mathrm{j} \omega \mathrm{Q} .
$$

Then, by combining (19-a) and (20), for each $\omega_{\mathrm{k}} \in\left[\omega_{\min }: \omega_{\max }\right], \mathrm{Q}\left(\omega_{\mathrm{k}}\right)$ is computed by

$$
\mathrm{Q}\left(\omega_{\mathrm{k}}\right)=\frac{-2 \mathrm{v}_{0 \Phi}}{2 \mathrm{v}_{0 \mathrm{Q}}+\left(\mathrm{R}+\mathrm{jL} \omega_{\mathrm{k}}\right) \mathrm{j} \omega_{\mathrm{k}}}
$$

By using (19-b), (19-c) and (19-d) and $Q\left(\omega_{k}\right)$, we can calculate v, $\mathbf{A}$ and $\mathbf{u}$. E, $\mathbf{B}$ and $\mathbf{S}$ can be also deduced from (7), (8) and (9). Figure 6 presents the real part of the deformation obtained from the reduced model at the mechanical resonance $(\mathrm{f}=73.9 \mathrm{kHz})$. Three cases are considered such as the open circuit, $\mathrm{R}=4 \mathrm{k} \Omega$ and $\mathrm{R}=50 \Omega$ with $\mathrm{L}=10 \mathrm{mH}$. Figures 7 and 8 present the evolutions of the voltage magnitude and of the maximal deformation versus the frequency. Then, the maximal magnitude of the voltage decreases when the modulus of the load increases. For the last case $(\mathrm{R}=50 \Omega, \mathrm{L}=10 \mathrm{mH})$, an electric resonance can be observed on Fig. 7 for a frequency equal to $27.8 \mathrm{kHz}$. This resonance influences the maximal deformations. For all cases, the relative errors on $\mathrm{v}_{0}$, $\operatorname{def}_{\mathrm{x}}$ or def $_{\mathrm{y}}$ between the full and PGD models are smaller than $0.01 \%$ and the speed up is equal to 53 . We can see also that, at the contrary to an equivalent electric circuit based on lumped parameters, the link with the full model is kept. In fact, the field distributions can be determined very quickly if necessary from the reduced model. This is not the case with an equivalent circuit which requires, if the field distributions are needed, the solution of the full model.

\section{CONCLUSION}

The Proper Generalized Decomposition has been applied to a magnetoelectric problem to build a reduced model (Offline stage). Then, the PGD reduced model has been coupled with an electric load in order to study the device in its environment during an Online stage. The PGD approach and the use of a reduced model enable to reduce the computational times compared with a full model while maintaining good accuracy and an access to any local and global quantity.

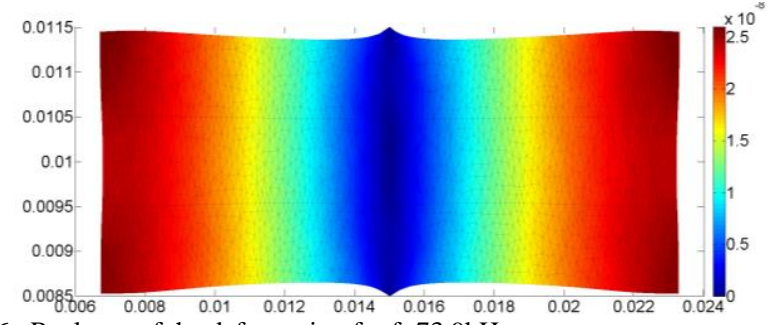

Fig. 6. Real part of the deformation for $\mathrm{f}=73.9 \mathrm{kHz}$.

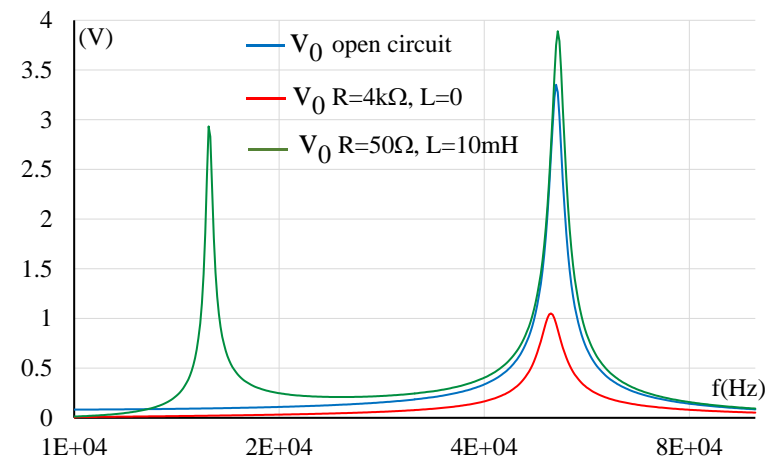

Fig. 7. Magnitude of the voltage versus the frequency for different values of electrical load.

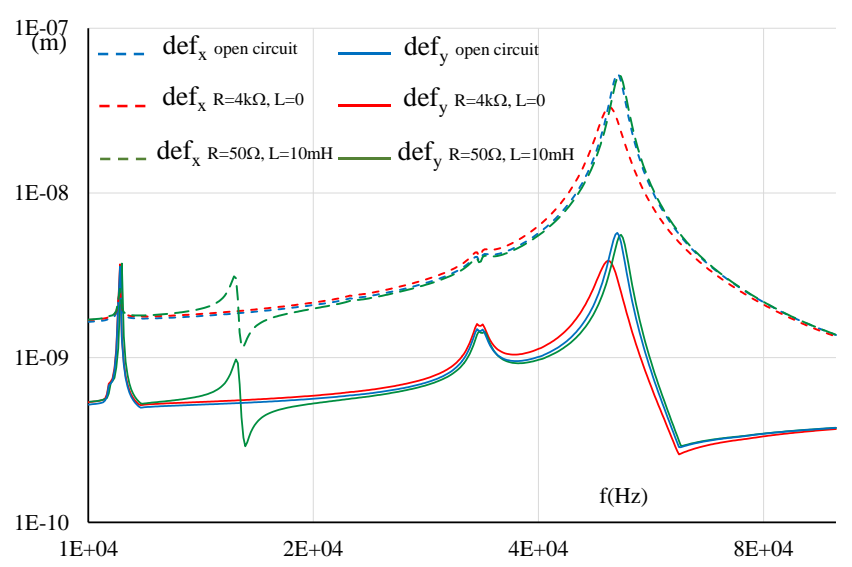

Fig. 8. Maximal deformations along $\mathrm{x}$ and $\mathrm{y}$ versus the frequency for different values of electrical load.

\section{REFERENCES}

[1] F. Chinesta, R. Keunings and A. Leyguel, The Proper Generalized Decomposition for Advanced Numerical Simulations, A. Primer, Springer International Publishing, 2014.

[2] E. Pruliere, F. Chinesta and A. Ammar, "On the deterministic solution of multidimensional parametric models using the Proper Generalized Decomposition", Numerical Methods in Engineering, Mathematics and Computers in Simulation, Elsevier, vol. 81 (4), pp.791-810, 2010.

[3] P. Alotto, M. Guarnieri, F. Moro, A. Stella "A proper generalized decomposition approach for modeling fuel cell polymeric membranes" IEEE Trans. Mag., vol. 47( 5), pp. 1462-1465, 2011.

[4] T. Henneron, A. Benabou, S. Clénet, "Nonlinear Proper Generalized Decomposition Method Applied to the Magnetic Simulation of a SMC Microstructure", IEEE Trans. Mag., vol. 48(11), pp. 3242-3245, 2012.

[5] T. Henneron and S. Clénet, "Application of the PGD and DEIM to Solve a 3-D Non-Linear Magnetostatic Problem Coupled With the Circuit Equations", IEEE Trans. Magn., vol. 52, no. 3, 7202104, 2016.

[6] M. Pineda-Sanchez et al., "Simulation of skin effect via separated representations", COMPEL, vol. 29(4), pp.919-929, 2010.

[7] T. Henneron and S. Clénet, "Proper generalized decomposition method applied to solve 3D magnetoquasi-static field problems coupling with external electric circuits", IEEE Trans. Magn., vol. 51, no. 6, pp. $7208910,2015$.

[8] Z. Qin, H.Talleb and Z.X. Ren, "A proper generalized decomposition based solver for nonlinear magneto-thermal problems", IEEE Trans. Magn., vol. 52, no. 2, pp. 7400209, 2016.

[9] Z. Qin, H. Talleb, S.Yan and Z.X. Ren, "Application of the PGD in Parametric Finite Element Simulation of a Piezoelectric Energy Harvester", 10th International Symposium on Electric and Magnetic Fields (EMF 2016), (Lyon) France, 2016.

[10] X. Mininger, H. Talleb and T. Henneron, "Review on Numerical Modeling of Magnetoelectric devices", International Compumag Society Newsletter, vol. 23(3), 2016. 